S U R GER Y.

\author{
UNDER THE CHARGE OF \\ J. WILLIAM WHITE, M.D.. \\ JOHN RHEA BARTON PROFESSOR OF BUROERY IN THE UNIVERSITY OF PENNGYLVANIA; \\ BUROEON TO TEE UNIVERSITY HOSPTTAL, \\ AND \\ T. TURNER THOMAS, M.D., \\ ABSISTANT GURGEON TO THE UNIVERSTT AND PHILADELPHIA HOSPITALS, AND AGSISTANT \\ INSTRUCTOR IN BUROERY IN THE UNIVERSTTY OF PENNSYLVANIA.
}

Transdiaphragmatic Massage of the Heart in a Case of Apparent Death in the Newborn.-VAnverTs (Annales de la Société Bolge de Chirurgie et Journal de Chirurgie, October, 1905) was called in consultation in a case of difficult labor. The foetal lieart sounds werc rapid but strong. Version was performed. During the disengagement of the arm the child made an inspiration in utero. When born it was apparently dead. The heart-beat could not be detected, but in the epigastric: region there was a eontinual trembling movement. Artificial respiration, "mouth to moutl," for twenty-five ninutes and hot baths were without result. The epigastrie tremors continued.

Througl an incision along the left costal border two fingers were introduced into the abdominal cavity. When they touched the diaphragm an inspiration occurred. Rhythmical massage of the heart was then carried out by compressing it between the fingers inside and the other hand on the chest outside. No cardiac contraction was felt at any time. From time to time for five minutes an inspiration took place, the interval while not accurately observed being from a halfminute to a minute. At the end of five minutes they disappcared entirely, the epigastrie tremors ceasing also.

The writer emphasizes two points in this ease: (1) The cardiac massage did not produce a cardiac contraction: the only result was faulty respiration for a short time. (2) The first inspiration. excluding that which occurred in utero, was produced when the fingers touched the diaphragm and before the heart was compressed. The writer thinks that in these conditions, although a cardiac contraction may occur later, it is the touching of the diaphragm and not the eardiac: massage which originates the reflex causing the first inspiration. If this is so, then this paper should have been entitled "The Production of Inspiratory Movements by Excitation of the Diaphragm."

The Ventral Decubitus in Surgery.-LambotTe (Annales de la Société Belge de Chirurgie et Journal de Chirurgie, October, 1905) believes that the introduction of the ventral decubitus marks an important advance in surgery, and that the operative technique and the indications for many operations will be modified by it. It is applicable to all operations on the posterior surface of the body; as trephining in the occipital region, operations on the back of the neck, shoulders, vertebral columin, lungs, posterior surface of the liver, sacrum, pelvic organs, and the posterior surface of the extremities. 
The patient is first anæsthetized in the dorsal position and then turned absolutely on his face. The arms are permitted to hang from the sides of the table and the extremities to remain in the extended position or to hang from the table according to the necessities of the case. Pads or cushions may be used to elevate this or that part of the body, when desired. Anæsthesia is remarkably easy in this position as compared to the lateral, which Lambotte finds to be a striking advantage in empyema operations. Some cancers of the rectum operated on successfully in this position had bcen considered inoperable by the old methods. The sacral route offers great advantages for the removal of cancel of the uterus. Two operations were performed for double kidney involvement. One was a double decortication, and the other a double decortication and nephropexy. No change in position is necessary during the whole operation. He reports twenty operations of various kinds done by this method.

Observations on the Removal of the Vermiform Appendix.-Kolliker (Zentralblatt $f$. Chirurgie, October 14, 1905) says that he has made use of an ineision, during the past year, whieh produces a slight wound, and guards against ventral hernia later, as effectually as does the suture of the wound in layers. It is a slightly oblique incision, beginning at McBurney's point and running in the direction of the symphysis pubis for about $8 \mathrm{~cm}$. After the division of the skin and subcutaneous tissues the aponeurosis of the external oblique muscle and the anterior layer of the sheath of the rectus for its outer third or half are divided. The border of the rcctus musele is then separated from its sheath and held aside by a retractor. The tendinous fibres of the internal oblique and transver-alis fascia as we $\mathrm{l}$ as the transversalis are then separated. The ineision in the peritoneum is made small, 3 to $4 \mathrm{~cm}$. This incision has the advantage that the peritoneal portion of it lies chiefly under the rectus muscle, and that no muscle has becn divided except a few tendinous fibres of the internal oblique and transversalis. In the closing of the wound the peritoneum is sutured separately and the rectus muscle overlies the suture. A second suture seizes all the other layers together.

If after opening the abdomen the visceral relations are distorted and the search for and separation of the appendix gives trouble, the incision can be lengthened at both ends in order to give a better view of the relations. For these cases Kölliker calls attention to two points. The position of the appendix can easily be found if the excum is freely exposed and the anterior longitudinal band of the crecum is followed carefully. The twisted appendix draws the longitudinal band in its direction. If the internal band is convex it speaks for a retrocæcal position of the appendix. If the external longitudinal band is convex then the appendix is situated on the inner side of the crecum or in the pelvis. Zuckerkandl considers that these varieties are physiological; Kölliker believes that they are due to inflammatory changes.

The Etiology and Treatment of Hernia in Adults.-Russeld (Intercolonial Medical Journal of Australia, September 20, 1905) says that acquired hernia does not exist in children; that it is invariably dependent upon the presence of a congenital sac, which in the great majority of cases is provided by some portion of the process vaginalis. Only by the complete removal of the sac from the inguinal canal can the 
hernia be cured, the so-called curing of the hernia by the usc of a truss being a deceptive misnomer.

'The writer believes that the direct inguinal, femoral, obturator, and all varieties of hernia other than traumatic are due to the presence of a congenital peritoneal pouch. The best test of this is the fact that the simple removal of the sac cures the hernia in children. The writer has applied the same test in eighty-nine adult herniæ. The canal was not closed by sutures, except in one or two of the carliest cases. 'The list includes subjects of all ages and hernix of various duration. Of the eighty-nine cases, twenty-six could not be traced. Of the sixty-thrce remaining, recurrence took place in three, taking one year's immunity as the standard of success. Russell agrecs with Deanesley that recurrence, if it occurs at all, does so in the vast majority of cases within the first six or eight months from the time of operation. In adults, unlike children, because of the length and obliquity of the canal, it is not possible to get at the peritoneum, at or above the internal ring, without slitting up the external oblique. In adults from prolonged stretching and dilatation the canal becones converted into a large hole in the abdominal wall. Any portion of the peritoncum exposed below the muscular border of the internal oblique and transversalis must be considercd a part of the sac and removed. The transversalis fascia should be included in the ligature closing the sac, the inner part of which, especially, is to be drawn up by the ligature. Sutures of the muscles are not nccessary, the essential for success being the removal of the sac.

Simplified Operation for Hernia in Children.-HerRING (Intercolonial Medical Journal of Australia. September 20, 1905) has devised and practised as a corollary to Mr. Russell's thcory (see aloove) a method of shortening the radical operation for hernia in children. The sac is exposed and opened in the usual way, the contents are reduced into the abdominal cavity, and the incision having been extended to the neck, the sac is turned inside out, exposing the peritoneal surface. The neck of the sac is then divided transversely and the upper cut end closed. The wound is then closed by a subcuticular suture. The sac, having been turned inside out, is left to shrivel up quietly, and an operation ordinarily requiring three-quarters of an hour is reduced to one taking a few minutes.

The Treatment of Racemose Arterial Angioma of the Scalp.-Krogrus (Zentralblatt f. Chirurgie, Septcmber 30, 1905) has cmployed the following treatment, with success, for cirsoid aneurysm of the scalp. He used two needles, each furnished with a handle, onc handle having a slightly curved ncedle, the other a more marked curve. Both were capable of bending considerably. The needle with the greater curve was passed through the skin to the skull, then along this for a short distance and out tlirough the skin. After being threaded with a strong catgut ligature it is withdrawn, leaving the ligature in position. 'Through the same point of entrance the second needle is passed and its point made to emerge at the second opcning, the track of the needle being just under the skin. The end of the ligature at the sccond opening is now threacled into the necdle and withdrawn through the first. The ligature, which includes in its loop the thickness of the scalp, excluding 
the skin, is now tied at the first opening and the ends removed. Other such ligatures are placed, one close to the other, so as to form a ehainlike series around the whole tumor, thus shutting off the greater part of its blood supply and causing a shrinkage of it. If the first operation is not a complete suecess, and more or less of the angioma is left, a second smaller ring of ligatures nay be applied around the remaining part of the tumor. The operation may be repeated until the angioma has entirely disappeared.

Four Unusual Cases of Aneurysm.-Locke (Boston Medical and Surgical Journal, December 14, 1905) says that the first patient was a man, aged thirty-six years, who had syphilis in youth; tuberculosis of both hips for twenty-five years; double inguinal hernia; marked arterioselerosis; relative mitral insufficiency; tabes dorsalis; chronie interstitial nephritis; deformity of the spine; and aneurysul of the left axillary artery, possibly following trauma, which reached an enormous size and finally uleerated externally, with death after five days.

'The seeond patient, a colored woman, aged sixty-six years, had arteriosclerosis; aneurysm of the transverse aorta, the first sign of which was hæmatemesis. Nine days later she had a second attaek, with death after ten hours, from ulceration and hemorrhage into the csophagus at the level of the bifureation of the trachea.

The third patient, a man, aged thirty-six years, had syphilis twelve years ago, and later developed a sacculated aneurysin of the abdominal aorta, with rupture into the retroperitoneal tissue and subsequent erosion of the vertebra, hydrothorax, atrophy of the left kidney, and arteriosclerosis. An exploratory laparotomy showed a large pulsating tumor oceupying the entire upper left quadrant of the abdomen. He was doing well five days later, when he suddenly eollapsed with signs of hemorrhage, four months after the onset of the symptoms.

The fourth patient, a male, aged eighty-one years, showed general arteriosclerosis, multiple aneurysm of the ablominal aorta with ulceration into the third portion of the duodenum, and hemorrhage into the stomaeh and intestines. The symptoms extended over a period of four months. Death occurred four days after rupture.

Contribution to the Surgery of the Prostate Gland-BARKer (New York and Philadelphia Mediral Journal, Deeember 16, 1905) thinks that the time when prostateetomy should be done should be settled as definitely as it has been settled for appendieitis. The use of the catheter by the patient sliould be condennned, because infection invariably follows, and beeause it encourages the patient to put off the operation until what should be a benign operation becomes a langerous one. By early operation years of invalidism are avoided. 'Three essential points in the operation should be aimed at: minimizing the loss of blood, a short operation, and the least possible traumatism. Barker prefers the perineal operation by an inverted U-shaped ineision, beginning two-thirds of the distanee between the anus and the tuberosity of the ischium, earrying it over the bulb of the urethra and baek to a eorresponding point on the opposite side of the anus. It affords the maximum of room, enables the operator to see every step of the operation, and avoids the angular flap of the inverted $\Lambda$ incision. The various steps of the operation are then deseribed. The sphineter 
is divided carly in the operation, and later sutured in position again. The membranous urethra is divided on the grooved staff, a special prostatic tractor is introduced into the bladder and its blades opened. By elevating the handle as a lever and using the pubes as a fulcrum the prostate is brought into the opcrative field and enucleated. 'To break up the tough bands firmly uniting the gland to the capsulc a forceps, with teeth, is used as a tissue crusher. A good-sized drainagc tube wrapped with gauze is introduced into each lateral cavity and brought out of each of the two lower eorners of the wound. As large a catheter as possible is introduced through the penis into the bladder and retained, for the escape of urine into a urinal and for washing the bladder. 'The drainage tubes are removed in forty-eight hours. 'The writer has treated thirty cases in this way, losing one patient who died of senile pneumonia. As for the retention of virility after the operation, so far as he knows, no one has reproduced after this operation.

A Note on Prostatectomy for Hypertrophied Prostate.-Loumenu (Annales des Maladies des Organes Genito-Urinaires, December 15, 1905) bclieves that the total transvesical prostatectomy of Freyer offers little opportunity for improvement, judging from his own short experience and the brilliant and abundant results of the promoter of the operation. In four cases, however, in which he diagnosed hypertrophy of the lateral lobes, he failed to enucleate these lobes by the method of Freyer. By cutting through the infcrior bladder wall at the summit of each prostatic lobe, with the right index finger through this incision he was able to isolate and extract the lobes. He considers that the transvesical enucleation of a sound and normal prostatc is wellnigh impossible. On the contrary, an adenomatous gland, even if very small, can be perfectly enucleated, although this will be much more difficult than in the case of an hypertrophy of large dimensions.

On Some Recent Advances in Urology.--Heiczuann (Boston Medical and Surgical Journal, December 21, 1905) says that the most frequently employed new method of recent years is cryoscopy. This is the determination of the freezing point of blood and urine, which varies according to the number of molecules a solution contains. It is not entirely trustworthy. The methylene blue, phloridzin, electric conductivity, and toxicity tests are not at all reliable. No surgeon should determine upon the removal of one kidney before he has satisficl himself of the functional activity of the other, but no unanimity as to the method to be employed has yct bcen attained. When thic examinations are carefully conducted the microscope is undoubtedly of extrence aid in the diagnosis of inany lesions of the genitourinary tract, as the inajority, though not all, cpithelial cells in the urine are characteristic cnough to admit of their location. Not only can nephritis be diagnosed when true tube casts are not present, but also pyelitis, ureteritis, cystitis, prostatitis, and other inflammations, as wcll as suppurations, ulcerations, and many other conditions. One may judge the constitution of the individual by the character of the pus corpuscle. Microscopic urinalysis of catheterized urines of separate kidneys is much more trustworthy than other methods of determining the functional condition of the kidneys. 
A Case of Acute Hemorrhagic Pancreatitis; Operation; Recovery.Jones (Liverpool Medico-Chirurgical Journal, January, 1906) made a diagnosis of some gastric lesion, possibly a perforated gastric ulcer. On opening the abdomen about three pints of free fluid, bright blood mixed with serum, issued from the cavity. The presence of fat necrosis at the entrance of the lesser peritoneal cavity led to an opening through the gastrocolic omentum, which disclosed a discolored cedematous and in places hemorrhagic pancreas. After cleaning out the blood and packing around the pancreas with gauze a longitudinal incision was made in the pancreas. No stone, absccess, or other cause was found. The cavity in the pancrcas was packed with gauze, whicll was brought out of the wolmd. This was carefully removed in thirtysix hours, being followed by a discharge of clear pancreatic fluid which gave trouble at the upper part of the abdominal wound. Healing was complete, and the patient discliarged cured in about ten weeks after the operation.

Cholerrhagia in Hydatid Cysts of the Liver.-Terrier and DUJARRier (Revue de Chirurgie, January 10, 1906) says that (holcrrhagia after the marsupialization of hyatid cysts of thc liver is a frequent complication. Two forms should be distinguished: (1) Partial cholerrhagia, much the more frequent, which ceases spontaneously in a varibble time, without notable disturbance of the process of healing. (2) Total cholerrhagia, inuch less frequent without being very rare. It is sometimes accompanied by very grave symptoms and may be fatal. As a rule, it undergoes spontaneous cure, but in some cases it may demand a serious operation to save the patient's life. The writers report three cases of this kind from the literature, which were all that they could find.

That this condition exists before operation is shown by the fact that on opening it the cyst is found to contain bile. It was formerly claimed that bile in a cyst would curc it, and that the bile would kill the parasites. Dévé cites a case in which a cyst ruptured into the biliary passages, and the daughter cysts were engrafted on and continued to live in the biliary ducts. In some cases the cholcrrhagia occurs at the time of operation. It occurs much more frequently in the first twenty-four hours, its presence being detected at the first dressing. It is also frequently seen some days or weeks after tlie operation. In other cases it occurs late when there remains only a fistula, or even after complete cicatrization of the wound. In a case of Kehr's the common bile duct became blocked and the increased pressure in the biliary paths caused the scar to yield with an cscape of bile (secondary or consecutive cholerrhagia).

Between the partial and total varieties all grades occur. When total the absence of bile in the feces shows that none is passing into the intestines. In such cases the dressings may be saturated several times a day. The disappearance of the cholerrhagia depends on one of two facts: the closing of the wound in a biliary duct, or the elimination of a biliary obstruction. Suppuration does not appear to play an important part in its causation. When the condition lasts a long time the patient succumbs either to a progressive cacliexia or to an intercurrent complication which he cannot withstand. When due to trauma the cause is easily explained, the biliary passages being opened at the time of the 
operation, or during the dressing by a forceps, a drain, or a trocar. In the grcatcr numher of tardy cholcrrhagias, appearing months after operation, at times after the cicatrization of the wound, the cause will be some obstacle in the biliary passages. This may be an obstruction by daughter cysts, a tumor, or inflammation of the common bile duct or ampulla of Vater.

The treatment should be prophylactic and curative. The prophylactic consists in avoiding as far as possible injury to the often denuded, dilated, and friahle biliary canals, especially in the removal of the parent membrane of the cyst, and in avoiding unneccssary interference afterward. In the suppurating cysts the membrane is more adhercnt and requires more care in its removal.

Abscess of the Liver and Precocious Cholerrhagia.-VAlence (Revue de Chirurgie, January 10, 1906) says that precocious cholerrhagia is the escape of bilc, pure or mixed with pus, during the twenty-four hours following the incision into an abscess of the liver. It is distinct from primitive and secondary cholerrhagia. The sccondary variety occurs when the biliary canals have opencd into the pus cavity by the separation of the sloughs, that is, some days after the operation. It ceases when the process of repair is sufficiently advanced. Thrombi of the biliary vessels may also be dislodged by the pressure of the biliary current. Valence believes that with care the drains ought not to produce clolerrhagia, from the hypcrsecretion of irritation, nor by ulceration into the biliary vessels. Irrigation of the abscess cavity is not responsible for precocious cholerrhagia, since this occurs before the first change in the dressings is made. Of four cases of the precocious variety, collcctcd from the literature, in only one case was curettage done, so that this is not the essential cause.

Bertrand considers that a cholerrhagia is a serious symptom, and is to the biliary vessels what hemorrhage is to the bloodvessels. When excessive it tends to ruin the nutrition. The writer attributes a costal caries in this patient to the dissolving action of the bile which came in contact with it. Catgut sutures will yield to its influence. Fontain advises that the abscess should be opencd widely, to permit rapid and complete evacuation, to avoid infection, and to favor prompt cicatrization. This would be the best means of abridging the duration of the biliary flow, and of attenuating its effects. 'The treatment for hemorrhage under the same circumstances should be carried out (thermocautery, tampon of iodoform gauze, and a gelatin solution of 1 to 10 per cent.). The writer believes that eversion of the edges of the abscess by suturing them to the skin, although adding to the time of the operation, is a good precaution against necrosis from the action of the bile. The skin should be protected from the bile by a smearing of vaselin. Internal treatment must be clirected against the failure in nutrition and emaciation.

Two Cases Illustrating Sciatica of Abdominal Origin.-Ross (Lancet, January 13, 1906) reports that in one ease the removal of a small, exceedingly tensc, central cystic tumor of the left ovary, about the size of a small orange, was followed by a complete disappearance of the symptoms of sciatica. The operation on the second paticnt resulted in death, but it was evident that a large tumor of the uterine cervix acted mechanically in producing the sciatica. 
Some of the Advantages and Fallacies of Urinary Examinations.SAVIDGE (Boston Medical and Surgical Journal, December 21, 1905) says that in almost all patients over forty who put the tension of concentration on their vasomotor system, faint traces of albumin can be found if the urine is examined often enough. 'This is especially noticeable with those who have overdeveloped venous calibres, whereby the extra capacity of the veins kceps an undue share of the whole volume of the blood in the veins as sewerage blood.

Certain forms of therapcuties can vary the specific gravity of blood; the output of urea can compass the solution of crystals which, like pepper in the eyc, must irritate the delicate kidncy substance and point to sure future trouble; and in thesc relaxed venous cases can even remove albumin by enhancing the tonicity of the vcins.

Having thus seen the relation between arterial tension by repeated laboratory use; between venous tonicity and albumin; between specific gravity and the appearance and disappearance of hæmoglobin; the following conviction has grown: varying these conditions will vary the laboratory findings; and the conditions may exist and be perfectly obscrvable some time before the laboratory will give any finding.

\title{
THERAPEUTICS.
}

\author{
UNDER THE CHARGE OF
}

REYNOLD WEBB WILCOX, M.D., LL.D.,

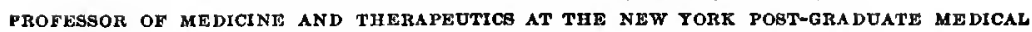
SCHOOL AND HOSPITAL; VISITING PHYSICIAN TO BT. MARK'S HOSPITAL.

\section{ASSISTED BY}

HENRY HUBBARD PELTON, A.M., M.D.,

INGTHUCTON IN MEDICINE IN THE NEW YORK POST-GRADUATE MEDICAL BCHOOL AND HOSPITAL; CHIEF OF THE MEDICAL CLINIC, PRESBYTERIAN HOSPITAL DIBPENSARY, NEW YORK.

Serum Therapy in Scarlet Fever.-W. K. METCHNikoff reports upon thirty patients treated by means of serum. In ten Moser's serum was employed and in twenty a serum was nsed that had been prepared hy Professor Sawtscheuko, in the laboratory of the University in Kasan, at the children's clinic of which the trcatment was carried out. All types of the disease were in the series and there was but one deatl, recovery without permanent complications occurring in the other instances. In the severe forms injections of six ounces or slightly more were given and were well borne, the pain at the site of injection seldom lasting longer than twenty-four hours. The influence of the treatment upon the course of the disease was most favorable, the temperature became lower, the pulse stronger, and the respiration slower; after from twelve to twentyfour hours the nervous symptoms would become less marked and the throat manifestations ameliorated. The serum, while it did not seem to prevent complications, rendered their course mild and favorable. Albuminuria was noted in four of the patients treated by Moser's serum, 